\title{
METODE PREVIEW, QUESTION, READ, SUMMARIZE AND TEST (PQRST) DALAM PEMBELAJARAN FIQIH UNTUK SISWA KELAS V MADRASAH IBTIDAIYAH (MI) DAYEUHMANGGUNG KABUPATEN GARUT
}

\author{
Ahmad Jaelani \\ Program Studi PAI/FPIK, Universitas Garut \\ e ahmadjaelani1919@gmail.com \\ Devi Nur Dianah \\ Program Studi PAI/FPIK, Universitas Garut \\ email: devinurdianah99@gmail.com \\ Krisandi Agis. S \\ Program Studi PAI/FPIK, Universitas Garut \\ email: Krisandi243@gmail.com \\ Yasya Fauzan Wakila \\ Program Studi PAI/FPIK, Universitas Garut \\ email: yasyafauzanalwakila04@gmail.com
}

\begin{abstract}
ABSTRAK
Selama ini fiqih diajarkan dengan metode yang relatif konvensional. Artinya, proses belajar mengajar dilakukan dengan cara penyampaian materi, dilanjutkan dengan menghafal dan praktik, sehingga bagi sebagian siswa terkesan monoton dan membosankan. Tidak jarang pula, karena alasan mengejar target kurikulum, para pendidik membebani siswa dengan materi yang begitu banyak tanpa memperdulikan apakah siswa telah benar-benar paham, tertarik dengan yang diajarkan atau tidak. Padahal suasana belajar yang monoton akan menciptakan suasana yang tidak nyaman, jenuh, bosan, bahkan bisa mengakibatkan stres. Kondisi yang tidak kondusif ini akan sangat menyulitkan untuk meningkatkan minat belajar fiqih dan tidak dapat mencapai hasil belajar yang optimal. Sehingga dibutuhkan suatu upaya pengembangan metode pembelajaran fiqih yang sesuai, tepat, dan menyenangkan. Penelitian ini bertujuan untuk memahami serta mengimplementasikan metode PQRST (Preview, Question, Read, Summarize and Test) dalam pembelajaran fiqih siswa MI Dayeuhmanggung Kabupaten Garut. Penelitian merupakan penelitian tindakan kelas dengan pendekatan kualitatif, sumber data merupakan primer yang diperoleh dari observasi dan hasil wawancara. Hasil penelitian yang diperoleh adalah metode PQRST (Preview, Question, Read, Summarize and Test) dalam pembelajaran fiqih pada siswa kelas V MI Dayeuhmanggung Kabupaten Garut dilaksanakan dengan baik, optimal dan efektif sehingga sikap minat belajar siswa meningkat.

Kata Kunci: belajar mengajar, fiqih, pengembangan metode
\end{abstract}

\section{Abstract}

During this time jurisprudence (Fiqh) is taught by relatively conventional methods. That is, the teaching and learning process is carried out by means of the delivery of 


\section{AL-ADABIYAH: Jurnal Pendidikan Agama Islam}

material, followed by memorization and practice, so that some students seem monotonous and boring. Not infrequently, for reasons of pursuing curriculum targets, educators burden students with so much material regardless of whether students really understand, are interested in what is taught or not. Though a monotonous learning atmosphere will create an uncomfortable, bored, bored, and even stressful atmosphere. Conditions that are not conducive will be very difficult to increase the interest in learning jurisprudence and cannot achieve optimal learning outcomes. So we need an effort to develop a method of learning that is appropriate, appropriate, and fun. This study aims to understand and implement the PQRST (Preview, Question, Read, Summarize and Test) method in learning fiqh of MI Dayeuhmanggung students in Garut Regency. Research is a classroom action research approach with a qualitative approach, the source of data is the primary obtained from observations and interviews. The results obtained are the PQRST (Preview, Question, Read, Summarize and Test) method in fiqh learning in fifth grade students of MI Dayeuhmanggung Garut Regency implemented properly, optimally and effectively so that the attitude of students' interest in learning increases.

Keywords: fiqh, method development, teaching and learning

\section{Pendahuluan}

Dalam proses pembelajaran, selalu ada tiga aspek penting yang saling terkait satu sama lain. Tiga aspek itu adalah materi yang diajarkan, proses mengajarkan materi, dan hasil dari proses pembelajaran. Banyak di antara pengajar hanya menyibukkan diri pada materi dan hasil belajar. Waktu mereka tersita untuk menyiapkan rencana pembelajaran serta perangkat-perangkat pembelajaran lainnya. Sementara upaya bagaimana mendisain proses pembelajaran yang baik sehingga tujuan pembelajaran dapat tercapai justru terabaikan.

Mengenai proses pembelajaran, selama ini mata pelajaran fiqih diajarkan dengan metode yang relatif konvensional. Artinya, proses belajar mengajar dilakukan dengan cara penyampaian materi, dilanjutkan dengan menghafal dan praktik, sehingga bagi sebagian siswa terkesan monoton dan membosankan. ${ }^{1}$ Tidak jarang pula, karena alasan mengejar target kurikulum, para pendidik membebani siswa dengan materi yang begitu banyak tanpa memperdulikan apakah siswa telah benar-benar paham, tertarik dengan yang diajarkan atau tidak. Padahal suasana belajar yang monoton akan menciptakan suasana yang tidak nyaman, jenuh, bosan, bahkan bisa mengakibatkan stres. Kondisi yang tidak kondusif ini akan

\footnotetext{
${ }^{1}$ Hasil observasi dan wawancara di MI Dayeuhmanggung Kab. Garut pada bulan Maret 2020. Hasil observasi dan wawancara tersebut menunjukan bahwa penyampaian mata pelajaran fiqh jarang menggunakan metode pembelajaran, sehingga membuat peserta didik mengalami kejenuhan dan kebosanan.
} 


\section{AL-ADABIYAH: Jurnal Pendidikan Agama Islam}

sangat menyulitkan untuk meningkatkan minat belajar siswa terhadap mata pelajaran fiqih dan tidak dapat mencapai hasil belajar yang optimal.

Dalam proses belajar mengajar, tentulah harus menggunakan berbagai metode yang sesuai dengan kondisi yang ada, agar tercipta suatu lingkungan belajar yang efektif dan efisien, yang membuat siswa menjadi menyenangkan dan semangat melakukannya. Sehingga dibutuhkan suatu upaya pengembangan metode pembelajaran fiqih yang sesuai, tepat, dan menyenangkan.

Fiqih merupakan ilmu yang membahas tentang hukum-hukum syara' yang berkenaan dengan amal perbuatan berdasarkan dalil-dalil. ${ }^{2}$ Dalam pelaksanaan pendidikan khususnya dalam suatu kegiatan belajar mengajar pembelajaran fiqih, baik disekolah maupun dimadrasah seorang guru sering kali ditemui mengalami kesulitan baik dalam memilih, menetapkan, serta menerapkan metode kedalam proses belajar mengajar.

Untuk itu, dibutuhkan suatu upaya pengembangan metode pembelajaran fiqih yang sesuai, tepat dan menyenangkan, sehingga pembelajaran fiqih dapat benar-benar tercapai tujuannya serta dapat memberi rasa senang bagi para siswa.

\section{Tinjauan Literatur}

Mata pelajarn fiqih merupakan mata pelajaran yang mengkaji tentang hukum-hukum syari'at Islam dari dalil-dalil yang terperinci. Pembelajaran bidang studi fiqh di Madarasah atau sekolah adalah interaksi pendidik dalam memberikan bimbingan kepada peserta didik untuk mengetahui ketentuan-ketentuan syari'at Islam. Materi yang sifatnya memberikan bimbingan terhadap warga peserta didik agar dapat memahami, menghayati dan mengamalkan pelaksanaan syariat Islam tersebut, yang kemudian menjadi dasar pandangan dalam kehidupannya, keluarga dan masyarakat lingkungannya. ${ }^{3}$

Bentuk bimbingan tersebut tidak terbatas pada pemberian pengetahuan, tetapi lebih jauh seorang guru dapat menjadi contoh dan tauladan bagi peserta didik dan masyarakat lingkungannya. ${ }^{4}$ Dengan keteladanan guru ini, diharapkan

\footnotetext{
2 www. http://digilib.uinsby.ac.id/8261/6/bab\%203.pdf di akses pada tanggal 11 Mei 2020.

3 Neneng Nafisah, Metodik Khusus Pendidikan Agama Islam. Metode Pembelajaran Fiqih. Modul 2. Universitas Garut. 2012, hlm. 68.

${ }_{4}^{4}$ Neneng Nafisah, Metodik Khusus Pendidikan Agama Islam. Metode Pembelajaran Fiqih. Modul 2 . Universitas Garut. 2012, hlm. 68-69.
} 


\section{AL-ADABIYAH: Jurnal Pendidikan Agama Islam}

para orang tua dan masyarakat membantu secara aktif pelaksanaan pembelajaran bidang studi fiqih di dalam rumah tangga dan masyarakat lingkungannya.

Adapun tujuan pembelajaran fiqh adalah untuk membekali peserta didik agar dapat mengetahui dan memahami pokok-pokok hukum Islam secara terperinci dan menyeluruh, baik berupa dalil naqli dan aqli serta mampu melaksanakan dan mengamalkan ketentuan hukum Islam dengan benar secara komprehensif. ${ }^{5}$

Pembelajaran fiqih, bukan hanya sekedar membahas teori, akan tetapi implementasi amaliah dari materi yang disampaikan. Selain itu pembelajaran fiqh harus mengandung unsur teori dan praktek. Belajar fiqih untuk diamalkan, bila berisi suruhan atau perintah, harus dapat dilaksanakan, bila berisi larangan, harus dapat ditinggalkan atau dijauhi. Oleh karena itu, fiqih bukan saja untuk diketahui, akan tetapi diamalkan dan sekaligus menjadi pedoman atau pegangan hidup. Untuk itu, tentu saja materi yang praktis diamalkan sehari-hari didahulukan dalam pelaksanaan pembelajarannya.

\section{Metode}

Penelitian yang digunakan adalah penelitian tindakan kelas (PTK) karena pada penelitian tindakan kelas dapat mengkaji permasalahan pembelajaran di dalam kelas melalui refleksi untuk memecahkan masalah dengan cara melakukan tindakan yang terencana dalam situasi nyata serta menganalisis setiap pengaruh dari perlakuan tersebut. ${ }^{6}$ Tindakan yang diterapkan dalam penelitian tindakan kelas terdiri dari empat tahap. Tahapan penelitian tindakan kelas (PTK) sebagai berikut: Pertama, Perencanaan, yaitu menyusun rancangan tindakan. (a) Mengidentifikasi masalah, (b) Mencarikan alternative pemecahan, dan (c) Membuat satuan tindakan (pemberian bantuan). Kedua, Pelaksanaan tindakan, yaitu implementasi atau penerapan isi rancangan, yaitu mengunakan tindakan dikelas. Kegiatan yang dilaksanakan dalam tahapan ini adalah melaksanakan tindakan upaya meningkatkan hasil belajar dalam pembelajaran mata pelajaran fiqih yang telah direncanakan. Ketiga, Observasi, yaitu pelaksanaan pengamatan. Dalam tahap ini dilaksanakan observasi terhadap pelaksanaan tindakan dengan

\footnotetext{
5 Neneng Nafisah, Metodik Khusus Pendidikan Agama Islam. Metode Pembelajaran Fiqih. Modul 2 . Universitas Garut. 2012, hlm. 69.

6 Zainal Arief, Artikel Penelitian Tindakan Kelas (Classroom Action Research). 18 hlm. Academia.Edu. hlm. 6.
} 


\section{AL-ADABIYAH: Jurnal Pendidikan Agama Islam}

menggunakan observasi yang telah dipersiapkan. Peneliti mempersiapkan lembar observasi yang telah disiapkan untuk mengetahui kondisi kelas terutama hasil belajar siswa dalam pembelajaran. Dalam penelitian ini hasil pengamatan kemudian didiskusikan dengan kolaburator yaitu guru mata pelajaran fiqih untuk dicari solusi dari permasalahan yang ada pada waktu pembelajaran berlangsung. Keempat, Refleksi, yaitu kegiatan untuk mengemukakan kembali apa yang sudah terjadi. ${ }^{7}$

\section{Hasil dan Diskusi}

Fiqih merupakan pengetahuan tentang hukum-hukum syariat Islam mengenai perbuatan manusia, yang diambil dari dalil secara terperinci). ${ }^{8}$ Artinya fiqih adalah ilmu yang menjelaskan tentang hukum syari'ah yang berhubungan dengan segala perbuatan manusia termasuk ucapan yang diambil atau disimpulkan dari dalil-dalil atau nash-nash syariat Islam.

Pembelajaran mata pelajaran fiqih merupakan bagian dari Pendidikan Agama Islam (PAI) yang bertujuan untuk menumbuhkan dan meningkatkan keimanan, melalui pemberian dan pemupukan pengetahuan, penghayatan, pengamalan serta pengalaman siswa dalam aspek hukum, baik yang berupa ajaran ibadah maupun muamalah, sehingga menjadi manusia muslim yang terus berkembang dalam hal keimanan, ketaqwaan kepada Allah SWT serta berakhlak mulia dalam kehidupan.

\section{Pembelajaran Fiqih}

Dari definisi yang dijelaskan, dapat disimpulkan bahwa pembelajaran mata pelajaran fiqih tidak hanya dilakukan di dalam kelas, akan tetapi seluruh kegiatan yang dirancang untuk mencapai tujuan fiqih. Selain itu, pembelajaran mata pelajaran fiqih juga banyak mengandung aspek nilai. Maka pembelajaran yang hanya mengarah pada aspek kognitif saja merupakan suatu kurang tepat dalam

\footnotetext{
7 Zainal Arief, Artikel Penelitian Tindakan Kelas (Classroom Action Research). 18 hlm. Academia.Edu. hlm. 8.

Sumber pendukung lainnya : Ardana, K., Suandi, N., \& Artawan, G. Pengaruh Penerapan Metode Membaca PQRST Ditinjau dari Minat Membaca terhadap Kemampuan Pemahaman Isi Bacaan Berbasis Teks Cerita pada Siswa. 2014. Hlm. 2.

8 Neneng Nafisah, Metodik Khusus Pendidikan Agama Islam. Metode Pembelajaran Fiqih. Modul 2 . Universitas Garut. 2012, hlm. 68.
} 


\section{AL-ADABIYAH: Jurnal Pendidikan Agama Islam}

proses belajar mengajar. Oleh karena itu, pembelajaran harus senantiasa mengarah pada tiga aspek, yaitu kognitif, afektif, dan psikomotorik.

Maka materi mata pelajaran fiqih perlu dikembangkan dalam suasana pembelajaran yang terpadu, yaitu meliputi, keimanan, pengamalan, pembiasaan, rasional, emosional, fungsional, dan keteladanan.

\section{Fiqih Qurban}

Kata qurban, berasal dari bahasa Arab, artinya pendekatan diri, sedangkan maksudnya adalah menyembelih binatang ternak sebagai sarana pendekatan diri kepada Allah SWT. Arti ini dikenal dalam istilah Islam sebagai udhiyah. Udhiyah secara bahasa mengandung dua pengertian, yaitu kambing yang disembelih waktu Dhuha dan seterusnya, dan kambing yang disembelih di hari 'Idul Adha. Adapun makna secara istilah, yaitu binatang ternak yang disembelih di hari-hari Nahr dengan niat mendekatkan diri (taqarruban) kepada Allah SWT dengan syarat-syarat tertentu.

Disyariatkannya qurban sebagai simbol pengorbanan kepada Allah SWT, bentuk ketaatan kepadaNya dan rasa syukur atas nikmat kehidupan yang diberikan Allah SWT kepada hambaNya. Hubungan rasa syukur atas nikmat kehidupan dengan berqurban yang berarti menyembelih binatang.

\section{Penerapan Tindakan}

Berikut ini penulisan mengungkapkan dan menganalisa data yang berkaitan dengan hasil penelitian sebagai berikut: Metode PQRST (Preview, Question. Read, Summarize and Test) dalam pembelajaran fiqih Madrasah Ibtidaiyah (MI) Dayeuhmanggung. ${ }^{9}$

Berdasarkan pra survey, sebelum penerapan metode PQRST (Preview, Question. Read, Summarize and Test), metode yang diterapkan oleh guru mata pelajaran fiqih di Madrasah Ibtidaiyah (MI) Dayeuhmanggung tempat penelitian, metode yang digunakan dalam pembelajaran mata pelajaran fiqih adalah dengan menggunakan metode ceramah dan tanya jawab. ${ }^{10}$

\footnotetext{
9 Penelitian dilakukan dengan teknik observasi dan wawancara pada MI Dayeuhmanggung Kab. Garut. Pada bulan Maret 2020.

10 Hasil observasi dan wawancara di MI Dayeuhmanggung Kab. Garut. Pada bulan Maret 2020.
} 


\section{AL-ADABIYAH: Jurnal Pendidikan Agama Islam}

Penelitian ini dilaksanakan dalam satu pertemuan dengan materi tentang "Mengenal Qurban". Hasil penelitian diuraikan dalam tahapan yang berupa siklussiklus pembelajaran yang dilakukan dalam proses belajar mengajar di kelas. Dalam penelitian ini pembelajaran dilakukan dalam dua siklus sebagaimana pemaparan berikut ini:

Perencanaan (Planning)

Dalam perencanaan pertemuan proses pembelajaran, peneliti menerapkan metode pembelajaran PQRST (Preview, Question. Read, Summarize and Test) dalam proses belajar mengajar dengan tujuan untuk meningkatkan hasil belajar pembelajaran siswa terhadap pokok bahasan materi tentang qurban. Adapun pada perencanaan ini peneliti mempersiapkan beberapa tahapan yaitu:

1. Membuat rencana atau gambaran pembelajaran dengan menggunakan metode pembelajaran PQRST (Preview, Question, Read, Summarize and Test).

2. Mempersiapkan bahan materi ajar yaitu tentang qurban.

3. Mempersiapkan lembar observasi untuk mengukur penggunaan metode pembelajaran PQRST (Preview, Question, Read, Summarize and Test) yang akan digunakan pada saat pembelajaran.

Pelaksanaan (Acting)

Pada pertemuan ini peneliti menjadi pelaku tindakan dalam mengajar mata pelajaran fiqih sekaligus peneliti mengadakan observasi proses pembelajaran yang dilakukan dalam mata pelajaran fiqih dan proses pembelajaran yang dilakukan oleh siswa. Untuk lebih jelasnya penerapan metode PQRST (Preview, Question, Read, Summarize and Test) dalam penelitian ini bisa dipaparkan sebagai berikut:

1. Kegiatan Awal

Pada awal pembelajaran peneliti langsung melakukan pengamatan dengan menggunakan lembar observasi mata pelajaran fiqih, memulai kegiatan pembelajaran dengan mengucapkan salam, berdo'a, setelah itu mengabsen siswa. Kemudian guru mata pelajaran fiqih memperkenalkan peneliti kepada siswa dan memberitahukan tujuan peneliti berada di kelas V Madrasah Ibtidaiyah (MI) Dayeuhmanggung tersebut. Selanjutnya guru menjelaskan kepada siswa bahwa mulai hari ini pelaksanaan

sumber landasan literatur: Ardana, K., Suandi, N., \& Artawan, G. Pengaruh Penerapan Metode Membaca PQRST Ditinjau dari Minat Membaca terhadap Kemampuan Pemahaman Isi Bacaan Berbasis Teks Cerita pada Siswa. 2014. Hlm. 2-3. 


\section{AL-ADABIYAH: Jurnal Pendidikan Agama Islam}

pembelajaran fiqih akan sedikit berbeda dengan hari biasanya, dimana pembelajaran lebih terpusat pada siswa, dengan cara yang lebih menyenangkan dan mengekspresikan kreativitas siswa. Pada waktu peneliti menjelaskan tentang strategi pembelajaran yang akan digunakan, siswa sangat antusias dengan memperhatikan penjelasan peneliti. Selanjutnya guru mata pelajaran fiqih memberikan waktu sepenuhnya kepada peneliti untuk membimbing siswa dalam pembelajaran mata pelajaran fiqih kelas V Madrasah Ibtidaiyah (MI) Dayeuhmanggung. Kemudian peneliti memberikan apersepsi dan motivasi kepada siswa sebagai langkah awal pembelajaran dan penerapan metode PQRST (Preview, Question, Read, Summarize and Test).

2. Kegiatan Inti

a. Langkah pertama, dimaksudkan agar siswa membaca dengan cepat sebelum mulai membaca bahan bacaan siswa yang memuat tentang isi materi yang akan dipelajarinya.

b. Langkah kedua, adalah menyusun atau mengajukan pertanyaan kepada diri sendiri mengenai isi buku setiap materi yang ada pada bahan bacaan siswa.

c. Langkah ketiga, siswa membaca secara teliti paragraph demi paragraph untuk lebih memahami isi bacaan atau materi yang ada dalam buku, sambil mencoba mencari jawaban untuk pertanyaanpertanyaan yang telah disusun tadi.

d. Langkah empat, siswa berhenti sebentar untuk meringkas atau membuat catatan penting mengenai apa yang sudah dibacanya tadi.

\section{Pengamatan (Observing)}

Pada pertemuan proses pembelajaran, hasil belajar siswa menunjukkan hasil yang bagus, baik dari segi korelasi materi dengan jawaban, keaktifan siswa, dan semangat dalam proses pembelajaran.

Refleksi (Reflecting)

Berdasarkan data hasil tes pada pertemuan proses pembelajaran, diketahui bahwa setelah menggunakan metode PQRST (Preview, Question, Read, Summarize and Test) dalam proses belajar mengajar mata pelajaran fiqih pada materi tentang qurban mengalami hasil yang cukup baik. Dari hasil pengamatan selama proses belajar mengajar berlangsung siswa mampu menerima apa yang peneliti 


\section{AL-ADABIYAH: Jurnal Pendidikan Agama Islam}

sampaikan, khususnya terhadap penerapan metode PQRST (Preview, Question, Read, Summarize and Test) pada materi tentang qurban.

Berdasarkan hasil penilaian pembelajaran dengan menggunakan metode PQRST (Preview, Question, Read, Summarize and Test) mampu memberikan kontribusi terhadap proses pembelajaran mata pelajaran fiqih di kelas dan menunjukkan jika setiap siswa memiliki interaksi dalam pembelajaran fiqih dengan semangat. Selain itu, pemberian reward atau hadiah merupakan wujud penghargaan atas hasil kerja dan keaktifan dalam pembelajaran. Sehingga hal ini berdampak pada hasil belajar yang meningkat.

\section{Kesimpulan}

Hasil dari penerapan metode PQRST sampai pada simpulan berikut:

1. Siswa kelas V di Madrasah Ibtidaiyah (MI) Dayeuhmanggung semangat dalam proses pembelajaran, sehingga terciptanya iklim kelas yang kondusif.

2. Siswa kelas V di Madrasah Ibtidaiyah (MI) Dayeuhmanggung aktif dalam pembelajaran, baik berinteraksi maupun menjawab pertanyaan.

3. Pemberian reward sebagai alat bantu dalam penerapan metode PQRST (Preview, Question, Read, Summarize and Test) bagi siswa yang aktif dalam proses pembelajaran merupakan cara yang efektif dalam meningkatkan hasil belajar siswa kelas V di Madrasah Ibtidaiyah (MI) Dayeuhmanggung.

4. Materi dapat tersampaikan secara terstruktur, sistematis, dan menyeluruh dengan mengaitkan gambar dan cerita pengalaman atau sejarah.

5. Dengan sifat keterbukaan dari metode PQRST (Preview, Question, Read, Summarize and Test) terdapat siswa yang terlalu aktif dalam proses pembelajaran, sehingga menjadi gangguan untuk siswa yang lainnya.

Berdasarkan hasil penelitian dan observasi, maka dapat disimpulkan bahwa melalui penerapan metode PQRST (Preview, Question, Read, Summarize and Test) dapat meningkatkan hasil belajar siswa pada mata pelajaran fiqih kelas $\mathrm{V}$ di Madrasah Ibtidaiyah (MI) Dayeuhmanggung.

\section{Referensi}

Ardana, K., Suandi, N., \& Artawan, G. (2014). Pengaruh Penerapan Metode Membaca PQRST Ditinjau dari Minat Membaca terhadap Kemampuan Pemahaman Isi Bacaan Berbasis Teks Cerita pada Siswa Kelas IX SMP 


\section{AL-ADABIYAH: Jurnal Pendidikan Agama Islam}

Negeri 2 Dawan. Jurnal Pendidikan Dan Pembelajaran Bahasa Indonesia, $3(1)$.

Arikunto, S. (2008). Penelitian Tindakan Kelas. Jakarta: Bumi Aksara.

Hidayah, N., Suwandi, S., \& Hastuti, S. (2014). Penerapan Metode PQRST Untuk Meningkatkan Minat Dan Kemampuan Membaca Pemahaman Siswa. BASASTRA, 2(3), 1-13.

Milasari, H., Mahfud, H., Sadiman, \& Sriyanto, M. I. (2015). Peningkatan Kemampuan Membaca Pemahaman Cerita Anak Melalui Metode Preview, Question, Read, Summarize, Test (PQRST). Jurnal Didaktika Dwija Indria, $3(7), 1-5$.

Nafisah, N. (2012). Modul Metodik Khusu Pendidikan Agama Islam, Modul 2. Garut: Universitas Garut.

Juhanaini. (2010). Penelitian Tindakan Kelas Penelitian Tindakan Kelas (Classroom Action Research). Bandung: Pendidikan Luar Biasa UPI.

Kunandar. (2011). Langkah Mudah Penelitian Tindakan Kelas. Jakarta: PT. Rajawali Pers.

Buku Paket Fiqih Pendekatan Saintifik Untuk Siswa Kelas V Madrasah Ibtidaiyah (MI), Direktorat Pendidikan Kementrian Agama Indonesia, Kurikulum 2013.

http://digilib.uinsby.ac.id/8261/6/bab\%203.pdf di akses pada tanggal 11 Mei 2020. 